\title{
The Beauty of Imagery in Tang Yin's Poetry
}

\author{
Wu Bo \\ Xianyang Normal University, Xianyang, Shaanxi Province, China, 712000
}

Keywords: Image; Flowers; Moon; Wine; Women

Abstract: Tang Yin's poetry highlights his wild and self-contained nature. The poetry style is full of love and fun. In his poetry, he used a lot of literary images such as flowers, moon, wine, and women to express his life's sentiments and ambitions in different periods. His poem style is unique.

In the middle of the Ming Dynasty, Tang Yin described his ideals of life, the style of the city, and achieved high literary achievements with his poetic style of true nature and love. His poetry language is easy to understand, and he is in harmony with his wild spirit. The imagery of his poetry is unique with natural charm.

\section{Flowers}

The aesthetic image of "flowers" is regarded as a typical representative of the imagery group of Chinese classical literature. In Tang Yin's poems, there are countless descriptions of flowers. For example, "The county court has a plum plant, I don't know when it is planted, and the shade is acre, and it is draped in the incense. It is more complicated to invade the snow, and it is more interesting." ("On the Plum Flowers") There are plum blossoms without fear of snow and cold. There are also "good colors with frost to open to the sun, fragrant strawberry and raspberry moss. The only pity is extraordinary, they have come to Tao Jun." (Picture of the Chrysanthemum), which describes the elegant, light and fragrant chrysanthemum; There are even more "enjoy the spring in the rich family in the rain, the streets and horses rise and fall." ("The Painting of Peony"), which describes the graceful peony. The poet vividly depicts the character of different flowers with delicate brushstrokes, which is full of vitality. Whether it is peony, plum blossom or a little red light in the flowers, it is full of poetry's hot feelings and good wishes.

"Shen Zhou's poems in the 'falling flowers' group in the 17th year of Hongzhi's poems have caused the pain of their bereavements. Later Tang Yi, Xu Yuqing, Wen Zhengming and others have made a difference." In this group of poems, or complex feelings, there are grievances of frustration in life; or seeing the red dust, there is a sense of freedom. Among the works, the number of injuries and the theme of the sense of falling flowers is the most prominent, revealing the poet's longing for and love for a better life. Those who love flowers and flowers, stand in the grass under the sun, and linger in the grass. For a long time, they can't bear to leave. After a while, they will send out the feeling that "Spring is not allowed to stay in the house, flowers and flowers are known to have nothing left? The new grass is invading the horizon green, the decline Yan also changed the mirror in the Zhu." Life is hurried, youth is easy to die, and why hasn't it been similar to the fate of this falling flower. The falling flowers make the poets intoxicated, and the poet associates the flying 
flowers in the natural world with their own rough conditions. In the contrast, they don't feel sighed and sighed.

In addition, his preference for peach blossoms is almost paranoid. Tang Yan named his residence titled "Peach Blossoms" and wrote "Peach Blossoms". In the beginning, he wrote: "Peach blossoms in Taohuawu, peach blossoms under the peach blossoms; peach blossoms in peach blossoms, and peach blossoms are sold for wine." The word "Peach Blossom" appears repeatedly in the poem, and the theme is straightened, which visually creates a sense of beauty and exuberance of the hundreds of thousands of tree peach blossoms. The peach blossom image is not uncommon in Tang Yin's poems, such as "the wild shop peach blossoms are low, and the spring light is mostly in the west of the bridge." ("The painting"); "A small house outside Gusu City, Wanshu Peach Blossoms is full of moons." ("The wine is on the moon song"; "The flowers are blooming and full of village docks, and the wind and smoke are like Taoyuan Ancient." ("Peach Blossom Dock"). It can be seen that the poet's love for peach blossoms is extremely high. The poet's dream of being in the peach blossom is a vigorous vitality. The peach blossom image in Tang Yin's poetry also implies the image of a free and literate singer like a poet who is super-easy, wild, self-adapted and unconstrained by the world.

\section{Moon}

"Moon" has been sung by the literati since ancient times. In the ancient poems of Chinese dynasties, the image of "moon" is also too numerous to enumerate. Among them, Li Bai's image of the moon is most famous, such as "the moonlight in front of the bed, the suspect is the frost on the ground. Looking up at the moon, looking down on the hometown." ("Thinking on a Moony Night") and "toasting the moon, the film into three people." ("Drinking Alone in the Moonlight) and so on.

The moon in Tang Yin's works is often associated with his heart. He wrote in "The Love Song of the World": "The wind and the moon are inexhaustible, and the mountains and rivers flow in the same direction." This depicts the moon in the world with a sense of detachment from nature that is not worthy of fame and fortune. Another example is "Drunk to levy the princes and bright moons. It is said that this music can pass through the fairy." ("Fun in a Fishman's Home") The poet asked the wine for the month, and the impassioned lieutenant sent out the feeling of "rich in me like a cloud", and with the moon, expressing his fame and fortune, and he wants to stay away from the world. "Dreaming on the day, the dust is outside, and the song is drunk when the wind is clear." (On Wangchuan) In his poems, he portrays the clear and cold spirits of the moon, poetic, and also evokes the desire to be close to nature and away from the world.

There are also some moon-praising poems that hold deep love in the heart, such as "the mirror is shaped like a spring, the couple are in the same circle in front of the lamp. Everything is happy and thousands of people are drunk, and the world is idle." ("Sentiment") talks about a very happy life with Shen Jiuniang respecting each other, Qinshen and Ming. After Shen Jiuniang's death, Tang Yin in his later years felt lonely and hard. "The world is like a boat hanging a canopy, or moving to the West Bank or moving east. A few times the moon is still a full moon, a number of south winds and north winds. Long-term people have no good days, spring flowers are a few times red. Forbearance, half-deprecation is half-hearted." ("Warning the World") In this poem, the poet uses the gloom of the bright moon to express the joys and sorrows of the world, and expresses his nostalgia for the good past and the thoughts of Jiu Niang."2 Here, the moon has become the psychological sustenance of the poet.

\section{Wine}

"Wine" is often regarded as "poetry quote" by the literati. In the ancient literary world, poets such as Li Bai, Su Shi, Du Fu, Tao Qian, and Ruan Ji were known for drinking. They either use 
alcohol to drink, or drink wine, or drink wine, or express their feelings in wine. In short, these excellent poets use their unique talents to interpret the diverse literary and emotional connotations in the wine. Tang Yin is wild and self-sufficient. When you are happy, drink with your friends; when you are sad, think about the moon. It is not an exaggeration to say that the wine runs through the poet's life, and the wine is no longer a foreign object to the poet, but to some extent has been integrated into the poet's emotional life. The poet is associated with the wine, and the emotional connotation of their own in different periods are sent to the wine.

In the youth, Tang Yin's poetry was refined, and he created many poems that lived straight and lived happily. "Into the Wine Song" belongs to a more representative one of the works of this period. The style of this poem is similar to that of Li Bai's "Invitation to Wine". The work takes "wine" as the main line and surrounds Pi Zhuohe. Liu Ling is addicted to life, describing the joys of drinking. In the "Four Seasons in the Lower Reach of the Yangtze River", the poet outlines a drinking picture full of life and fun through the unique scenery and leisure life of the spring, summer, autumn and winter seasons. The narrative statements of the two poems are not lost, not monotonous, and complement the spiritual state of the poet's deliberate release. "In the 'Three Highs Songs', the authors around the historical allusions of Fan Yi, Lu Guimeng, and Zhang Han, pointing out that the three celebrities are all seemingly seclusion, but in reality they are the big men who are the best in the world." ${ }^{3}$ The whole poem expresses the praise and praise of the three poets. In the last two sentences, "Husband is a good man, and he dares to lick the old roots. I have lost a lot of wine in ancient and modern times. I also have a gull." This shows that the poet's desire to be effective in the ancients and the determination to help the world, but also reflects the poet's ambition and desire to be the world's life ambition. In "When the wine is on the moon song", the poet compares himself with Li Bai. He thinks that although Li Bai has the talents of heaven and earth, he still serves the emperor, but he is not as good as his own fame and is happy to live in the folk. After the completion of Peach Blossom Castle, the poet lived a long-awaited city hidden life. When he was free, he drank alcohol with his friends in the peach blossom forest. The relaxed and bright living environment made the poet's heart happy. From the "Green Water Red Bridge" apricot flower, several huts like Xianjia, the owner refuses to see the flower shop, the bag has the money and wine is not awkward." ("The painting poem") It can be seen that the poet's seclusion life is comfortable. At this time, the "wine" in the poems has the artistic conception of "indifferent and sincere" in Tao Yuanming's poems; the poor and the shackles and the stunned ones are the true portrayal of Tang Yin's life in his elderly. Although Tang Yin was optimistic, but in his later years, he recalled the past, and then look at the hunger and cold, and it will inevitably give a little sigh to the lonely life. "Sit on the yellow flower, and when you wake up, you still remember the madness when you are drunk; Dansha is a millennium medicine, and it is difficult to eliminate two frosts in the daytime." ("Thoughts") "There is a hate, and the full moon is forgotten." ("Ten Poem in Mengxing") From these verses, we can give the poet "the inexhaustible helplessness of the Tao, and the feeling of sadness and desolateness in the tens of thousands of wine glasses." ${ }^{4}$ For Tang Yin, the taste of "wine" is probably only known to him.

\section{Females}

It is not accidental that Tang Bohu's character can be circulated and developed in the long history. The distinctive character and background of the times and Tang Bohu's own "secularity" make him popular. Take the story of "Dian Qiuxiang" as an example, from the notes of "The Mirror of Misty Record" and "The Miscellaneous Notes of Yulin", to the movie TVs such as "Tang Bohu Sanxiao Marriage" and "Tang Bohu Point Qiuxiang", "Jiangnan Talented Tang Bohu", game novels such as "The True Story of Merry Talent" are all about the subject matter of Tang Bohu. In the 
stage of the literary drama, Tang Bohu's theme is more popular throughout the country, and the classics such as "Three Smiles Marriage", "Three Smiles" and "Tang Bohu" are in the local dramas of Qin Qian, Tan, Sichuan Opera and Peking Opera. They are widely spread. The reason why these "literary phenomena" are produced should be related to his image of "beauty".

In the poems, Tang Yin portrayed himself as "a golden guest in the dill team, and a smasher in the red powder." Moreover, the folk rumors about Tang Bohu's "three laughter stories", although not necessarily all true, are by no means unfounded. It is said that his second wife, Shen Shi, is also a singer, which shows Tang's romantic attitude towards life. Therefore, it is not difficult to understand that he paints and writes about beauty. Tang Yin has the "Eight Beauty of the Eight Immortals", which are the "beauty" in history such as Xue Tao, Wang Zhaojun, Zhuo Wenjun, Cui Wei, Yang Yuhuan, Green Pearl, Mei Lan and Bi Yu. These "beauty" are outstanding talents, and the fate is rough, probably by Tang Yan's self-sufficiency. In addition, most of the ordinary beauty he wrote is beautiful and simple: "Spring sleepy and frowning, combing into a loose curtain; Hand holding jasmine blush, want to insert people to ask if you want to satisfy the beautiful, holding jasmine. It is conceivable that the pink face and the blushing flowers complement each other and must be beautiful. It is no wonder that Yuan Hongdao would like to admire "pictures". Another example: "Unloading the cockroach, staying up late, lying late, pear flowers and calm birds; It's hard to say things to people and to say that they know what to do with the moon. In the dead of night, the "beauty" is full of heart, but no one talks, let "the sky" and "the moon" share this secret with themselves! The scenes are born, the poetry is swaying and moving, very touching.

Tang Yin has been lingering in the Qinlou Chu Pavilion for a long time, and he has frequent exchanges with the songs. This can be seen from his poem "Spring Day", "The New Year's Trail turns to the canopy, mostly in the Huanhua Temple." Yesterday, I was drunk even today, and I tried the wind and the wind. The bitter and dangerous rhyme invites you, and the warm clusters are smoked and dried. Send a message to all the friends in the club, can you feel the same as me? "His peach blossom dock is not only his own place, but also a place frequented by literati songs. "Beauties are gathered in the spring rain, when the time is new. The music string caress the fairy, the fork handshakes the wine to make a new. The day is not squatting, the gold is difficult to cast the mirror in the body. Mo resigned to the golden snail full, a smile never Victory is awkward." Although he sometimes does not have to play tricks, but more often, he praises the songs in the poems, the gentleness of the temperament, the skill, the skill, the skill is superb, but the fate is not good. In this type of poetry, he treats them with equal status and a well-informed attitude. Compared with similar poems, it not only has different content styles, but also reflects changes in personality concepts. Such as "Crying for Xu Su": Qingbo double traces are gone, love is long and resentful. The residual powder is yellow and silver, and the clothes are fragrant. The moonlight flower falls to the front of the lamp, and the spring is full of people from the dream. Then, if you are born, you are not old, so you can see each other. It is a memorial to the confidante, and I have never seen the special identity of the other party's "songs". The whole poetry is really cut and touching.

\section{Acknowledgement}

Fund Project: special scientific research project of Shaanxi Provincial Department of Education Project Name: The Heterogeneity of Tang Yin and his Poem and the Cultural Significance Project No.: 17JK0809

\section{References}

[1] Liu Chang. On Tang Yin's Poem [J]. Journal of Harbin University, January 2008.

[2] Yang Jihui. A Detailed Examination of the Case of Tang Yin[J]. Journal of Suzhou Education College, February 
2007.

[3] Deng Xiaodong, Wu Leya. Appreciation of Tang Yin's “The Fujian Temple of the sun and Chen Gong Shrine” - On Tang Yin's Pre-conceived Mentality [J]. Appreciation of Famous Works, November 2007.

[4] Wang Wenying.Tang Bohu's Life Journey and His Famous Thoughts [J]. Journal of Hebei Normal University (Philosophy and Social Sciences), March 2007. 